\title{
Tumor to Normal
}

National Cancer Institute

\section{Source}

National Cancer Institute. Tumor to Normal. NCI Thesaurus. Code C94998.

A common normalization of a tumor activity concentration, namely tumor activity concentration to normal tissue activity concentration. 